\title{
De novo synthesis of brominated dioxins and furans
}

\author{
Nuria Ortuño, Juan A. Conesa, Julia Moltó, and Rafael Font
}

Environ. Sci. Technol., Just Accepted Manuscript • Publication Date (Web): 19 Jun 2014

Downloaded from http://pubs.acs.org on June 19, 2014

\section{Just Accepted}

"Just Accepted" manuscripts have been peer-reviewed and accepted for publication. They are posted online prior to technical editing, formatting for publication and author proofing. The American Chemical Society provides "Just Accepted" as a free service to the research community to expedite the dissemination of scientific material as soon as possible after acceptance. "Just Accepted" manuscripts appear in full in PDF format accompanied by an HTML abstract. "Just Accepted" manuscripts have been fully peer reviewed, but should not be considered the official version of record. They are accessible to all readers and citable by the Digital Object Identifier (DOI®). "Just Accepted" is an optional service offered to authors. Therefore, the "Just Accepted" Web site may not include all articles that will be published in the journal. After a manuscript is technically edited and formatted, it will be removed from the "Just Accepted" Web site and published as an ASAP article. Note that technical editing may introduce minor changes to the manuscript text and/or graphics which could affect content, and all legal disclaimers and ethical guidelines that apply to the journal pertain. ACS cannot be held responsible for errors or consequences arising from the use of information contained in these "Just Accepted" manuscripts. 
1

2

TOC/ABSTRACT ART
Nuria Ortuño*, Juan A. Conesa, Julia Moltó, Rafael Font

\title{
DE NOVO SYNTHESIS OF BROMINATED
}

\author{
DIOXINS AND FURANS
}
Chemical Engineering Department. University of Alicante. P.O. Box 99, 03080 Alicante (Spain).

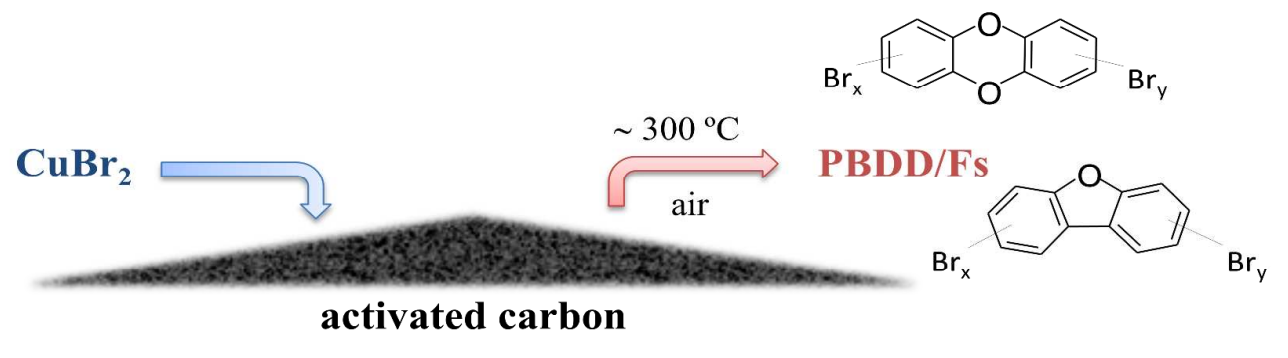

7

8 ABSTRACT

9 Based on laboratory experiments with model mixtures (active carbon $+\mathrm{CuBr}_{2}$ at different

10 loads), this work studies the formation of polybrominated dibenzo- $p$-dioxins and

11 dibenzofurans (PBDD/Fs) by de novo synthesis. For the different samples, the temperature

12 of the maximum carbon oxidation rate was determined by thermogravimetric analysis, and

*Corresponding author. E-mail: nuria.ortuno@,ua.es. Phone: + (34) 965903867 Fax: + (34) 965903826 
13 a kinetic model was proposed for the degradation of the materials in an oxidizing

14 atmosphere (synthetic air). The effect of the addition of different amounts of $\mathrm{CuBr}_{2} \mathrm{was}$

15 studied, finding that its presence accelerates the degradation of the carbonaceous structure

16 in the presence of oxygen. The thermal degradation of the samples in air is satisfactorily

17 described by a first-order single-reaction model. In addition, combustion runs of one of the

18 mixtures (consisting of activated carbon +50 wt. $\% \mathrm{CuBr}_{2}$, pyrolyzed at $700{ }^{\circ} \mathrm{C}$ ) were

19 performed in a quartz horizontal laboratory furnace. The analysis of the emissions and the

20 solid residue proved the formation of brominated dioxins and furans at 300,400 and

$21500{ }^{\circ} \mathrm{C}$, with maximum yield at $300{ }^{\circ} \mathrm{C}(91.7 \mathrm{ng} / \mathrm{g}$ of total $\mathrm{PBDD} / \mathrm{Fs})$ and a higher

22 bromination degree with increasing temperature.

\section{INTRODUCTION}

A prevalent pathway for the emission of chlorinated organic pollutants, including polychlorinated dibenzo-p-dioxins and dibenzofurans ( $\mathrm{PCDD} / \mathrm{Fs})$, has been recognized to be the synthesis of halogenated organic compounds in fly ash from combustion processes (e.g. sintering processes or municipal waste incinerators). Organic residual carbon and high molecular weight compounds from incomplete combustion have been found to be the precursor material for de novo synthesis, in the presence of chlorine and oxygen ${ }^{1-10}$.

As reported by Stieglitz et al. ${ }^{1}$, copper(II) ions were found to catalyze reactions on the surface of the particulate carbon in oxygen presence, promoting the oxidation of the carbon to $\mathrm{CO}_{2}$, as well as the formation of aromatic chlorinated/brominated compounds.

The formation of brominated organic compounds was also observed in the low temperature oxidation of carbonaceous materials, but the de novo synthesis of brominated $(\mathrm{PBDD} / \mathrm{Fs})$ and mixed chlorinated-brominated $(\mathrm{PXDD} / \mathrm{Fs})$ analogues in the presence of bromide has not been that extensively studied. In such a way, Heinbuch and Stiegliz ${ }^{11}$ substituted chloride by bromide in a fly ash, without changing its composition (especially 
38 the copper content, an essential catalyst in the de novo synthesis) and found formation of 39 many different aromatic brominated compounds (benzenes, biphenyls, thiophenes, 40 naphthalenes, benzonitriles and furans) during the thermal treatment of the ash. The 41 formation of these compounds started at $250{ }^{\circ} \mathrm{C}$, with a maximum production at $350^{\circ} \mathrm{C}$, 42 during a very long time (up to $120 \mathrm{~min}$ ) and increasing with the amount of added bromide.

43 Weber et al. ${ }^{12}$ reported on the formation of chlorinated-brominated dioxins and furans 44 via de novo synthesis from experiments with model fly ash in the presence of chlorine and 45 bromine. The resulting bromine/chlorine substitution ratio was studied in the range 250 $46350{ }^{\circ} \mathrm{C}$, being the bromine substitution less active at higher temperature and/or higher 47 residence time. The authors suggested similar substitution mechanisms for bromine and 48 chlorine during de novo synthesis, based on the similar isomer patterns found for 49 chlorinated, brominated-chlorinated and brominated dioxins ${ }^{12,}{ }^{13}$. Stieglitz et al. ${ }^{1}$ also 50 found that, in the presence of chlorine and bromine (molar ratio $\mathrm{Cl}: \mathrm{Br}$ of 10:1), mixed 51 chlorinated-brominated dioxins and furans were formed.

52 Examining the pattern of the dibromobenzenes, which showed a preference for the 53 ortho-position, Heinbuch and Stiegliz ${ }^{11}$ suggested two steps in the bromination of the 54 residual carbon on the fly ash surface. First, the bromination of the carbon surface, yielding 55 side by side orientation, followed by the oxidative decomposition of the carbon, separating 56 side by side substituted species.

57 In a pilot incineration plant, Schüler and Jager ${ }^{14}$ studied the formation of chlorinated 58 and brominated dioxins and other halogenated organic compounds. Results showed that $59 \mathrm{PBDD} / \mathrm{F}$ formation could also be explained by the reaction of brominated and mixed

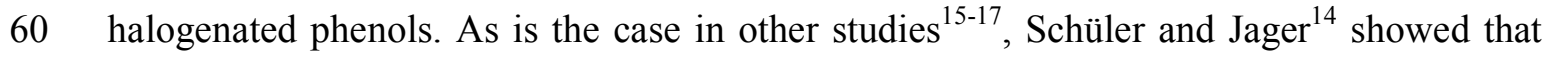
61 the efficiency of the post-combustion is more important than other parameters (i.e. 62 moisture, halogen proportions, temperature, air feed, dust or structure of the fuel). 
63 Du et al. ${ }^{18}$ suggested that the emissions of $\mathrm{PBDD} / \mathrm{Fs}$ in stack gas emissions from 64 industrial thermal processes is due to both de novo formation and also reactions of 65 precursors, mainly brominated flame retardants as polybrominated diphenyl ethers 66 (PBDEs) present in wastes from commercial products (e.g. electronic equipment, foams, 67 textiles,...), which can be used as alternative fuels in such processes.

68 Weber and $\mathrm{Kuch}^{13}$ also highlighted the fact that in waste incineration, the source of 69 chlorine are mainly inorganic compounds, minimizing the possible formation of PCDD/Fs 70 by the precursor pathway. However, the formation of $\mathrm{PBDD} / \mathrm{Fs}$ by precursor reactions 71 could prevail over the de novo synthesis, due to the presence of PBDEs, brominated 72 phenols and other brominated flame retardants as common sources of bromine in wastes.

73 Under efficient combustion conditions, these brominated precursors can be decomposed, 74 giving preference to the de novo synthesis in the formation of new PBDD/Fs, as is the case 75 of PCDD/Fs in municipal waste incinerators ${ }^{13}$.

76 Xiao et al. ${ }^{19}$ reported that the destruction of organobrominated compounds contained in 77 the electronic wastes could be very much effective, forming a mix $\mathrm{HBr} / \mathrm{Br}_{2}$ that reaches 78 thermodynamic equilibrium, and that is later a reagent for the formation of $\mathrm{PBDD} / \mathrm{Fs}$ on 79 the fly ash catalyzed de novo synthesis.

80 In a previous paper by Conesa et al. ${ }^{10}$, the de novo formation of PCDD/Fs was studied 81 both in a thermobalance and in a horizontal laboratory furnace, using model mixtures. In a 82 similar way, the present paper investigates the de novo synthesis of PBDD/Fs, considering 83 the following aspects:

84 1. Effect of $\mathrm{CuBr}_{2}$ in the combustion of activated carbon, at different loads.

852 2. Thermogravimetric kinetic study of the oxidation of activated carbon and different 86 model mixtures. 
87 3. Analysis of PBDD/Fs in the emissions from the combustion of a model mixture at 88 different temperatures $\left(300-500^{\circ} \mathrm{C}\right)$ to confirm the formation of such compounds 89 by de novo synthesis, and analysis of the influence of temperature. EXPERIMENTAL

\section{$91 \quad$ Materials}

92 For preparing the mixtures, an activated carbon (100-200 mesh) made by Euroglas

93 Analytical Instruments was used, as in the previous study ${ }^{10}$. This material is used for the 94 analysis of AOX (adsorbable organic halides), hence it has very low halide content. An 95 ultimate analysis of the sample was obtained with a Carlo Erba Instrument, model 96 CHNS-O EA110 and the results were 80.8 wt. $\% \mathrm{C}, 0.65$ wt. $\% \mathrm{H}, 2.0$ wt. $\% \mathrm{~S}$ and 970.24 wt. \% N. An analysis of chlorine (0.02 wt. \%) was carried out in an ECS 1600 98 Euroglas AOX analyzer and a confirmation was obtained by X-ray fluorescence ${ }^{10}$.

$99 \mathrm{CuBr}_{2}(99 \%$, Alfa Aesar) was mixed in different proportions and conditions with the 100 activated carbon. A total of five samples were studied:

101 - Activated carbon (Sample C).

102 - Activated carbon + very little amount of $\mathrm{CuBr}_{2}$ (approx. 0.15 wt. \%), with no further 103 treatment (Sample $\mathrm{C}+$ traceB).

104 - Activated carbon +1 wt. $\% \mathrm{CuBr}_{2}$, with no further treatment (Sample C+1B).

105 - Activated carbon +50 wt. $\% \mathrm{CuBr}_{2}$, with no further treatment (Sample C+50B).

106 - Activated carbon +50 wt. $\% \mathrm{CuBr}_{2}$, later pyrolyzed at $700{ }^{\circ} \mathrm{C}$ for $17 \mathrm{~min}(1000 \mathrm{~s})$ in

107 a quartz horizontal laboratory furnace, and washed for removal of $\mathrm{CuBr}_{2}$ excess $108 \quad$ (Sample py+wash $(\mathrm{C}+50 \mathrm{~B}))$

109 In this last case, the mixture was first pyrolyzed and then washed with an acidified 110 nitrate solution $\left(0.01 \mathrm{~mol} / \mathrm{L} \mathrm{NaNO}_{3}\right.$ acidified with $\left.\mathrm{HNO}_{3}\right)$, which causes competitive 111 desorption of inorganic halide species, removing the $\mathrm{CuBr}_{2}$ excess. In this way, the sample 
112 maintains the organically bound brominated compounds inside the carbonaceous structure,

113 but the subsequent combustion in the thermobalance is not affected by $\mathrm{CuBr}_{2}$

114 decomposition. An X-ray fluorescence analysis was carried out on the final sample, which 115 contained 4.2 wt. $\% \mathrm{Br}$ and 0.8 wt. \% Cu.

116 Pure $\mathrm{CuBr}_{2}$ was also decomposed in the thermobalance for comparing the different 117 behaviors.

118 All solvents for organic trace analysis were purchased form Merck (Germany) and the

119 unlabeled $/{ }^{13} \mathrm{C}_{12}$-labeled standards for PBDD/F analysis (EDF-5407, EDF-5408, EDF-5409

120 and EF-5410) were obtained from Cambridge Isotope Laboratories (Andover, USA).

121 Thermogravimetric analysis

122 The TG study was performed in a Mettler Toledo thermobalance (model 123 TGA/SDTA851e/LF/1600) with a horizontal furnace and a parallel-guided balance. The

124 sample temperature was measured with a thermocouple directly at the crucible, i.e., next to

125 the sample. Runs were performed at different heating rates $(5,10$ and $20 \mathrm{~K} / \mathrm{min})$, using 126 sample amounts close to $8 \mathrm{mg}$ and a flow rate of synthetic air of $100 \mathrm{~mL} / \mathrm{min}$ (STP). A

127 total of twelve duplicated runs were carried out for the present study.

128 According to the recommendations in specialized literature, runs were correlated 129 simultaneously in order to obtain one single set of parameters for each sample.

$130 \quad$ Experiments in laboratory reactor

131 Using a quartz horizontal laboratory furnace, previously described elsewhere ${ }^{20}$,

132 combustion runs were performed on the sample prepared by pyrolysis and subsequent 133 washing (sample 'py+wash $(\mathrm{C}+50 \mathrm{~B})$ '). The runs were carried out at 300,400 and $500{ }^{\circ} \mathrm{C}$ in 134 synthetic air, in order to check the formation of brominated dioxins and furans by the de 135 novo pathway at low temperatures. The volatiles evolved from the combustion runs were 
136 collected with a sorbent resin (polyaromatic Amberlite ${ }^{\circledR}$ XAD-2, Supelco, Bellefonte,

137 USA) placed at the outlet of the reactor during the entire run (60 min).

138 For each experiment, the resin and the residue (solid fraction remaining after the 139 combustion) were extracted separately with dichloromethane by Accelerated Solvent 140 Extraction in a DIONEX ASE ${ }^{\circledR} 100$. Prior to extraction, samples were spiked with a ${ }^{13} \mathrm{C}_{12-}$ 141 labeled PBDD/F internal standard solution (EDF-5408). All extracts were concentrated 142 down to $1 \mathrm{~mL}$ by rotary evaporation. After addition of a ${ }^{13} \mathrm{C}_{12}$-labeled PBDD/F cleanup 143 standard solution (EF-5410), the extracts were purified using an automated cleanup system 144 (Power Prep, FMS Inc., Boston, MA) with silica gel and alumina pre-packed columns. The 145 extracts were concentrated in a rotary evaporator and with a gentle stream of nitrogen for 146 analysis by gas chromatography coupled to high resolution mass spectrometry 147 (HRGC-HRMS).

148 The HRGC-HRMS analyses were performed on an Autospec Ultima NT mass 149 spectrometer (Micromass, UK) with a positive electron impact (EI+) source, provided with 150 an Agilent/HP 6890 Plus gas chromatograph (Palo Alto, CA, USA) with Programmed 151 Temperature Vaporization (PTV) and split/splitless injectors. The GC was equipped with a 152 TRB-Meta X5 Restek chromatographic column (15 m x $0.25 \mathrm{~mm} \times 0.25 \mu \mathrm{m})$ and the oven 153 temperature was programmed from 130 to $320^{\circ} \mathrm{C}$ at $10{ }^{\circ} \mathrm{C} / \mathrm{min}(15 \mathrm{~min}$ hold $)$, with a 154 carrier gas (helium) flow rate of $1 \mathrm{~mL} / \mathrm{min}$. The HRMS was operated in an electron impact 155 mode $(35 \mathrm{eV}$ and $650 \mu \mathrm{A}$ current) selective ion recording (SIR) mode at resolution $156>10000$ (10\% valley) and $290{ }^{\circ} \mathrm{C}$ as the temperature of the ion source.

157 The isotope dilution methodology was used to quantify the samples, using the relative 158 response factors previously obtained from the calibration standard solutions (EDF-5407159 CS1 to CS5). Recoveries of the spiked labeled standards were calculated using a labeled 160 recovery standard solution (EDF-5409) that was added to the samples prior to the injection 
161 on the gas chromatograph, obtaining the following recoveries: $31-129 \%$ for tetra- to

162 hepta-substituted congeners and $21-122 \%$ for octabrominated ones. A laboratory blank

163 was also prepared and analyzed together with the samples, as well as the activated carbon

164 itself, where no PBDD/Fs were detected.

165 Along all the experimental process, restrictive measures were adopted to avoid sunlight

166 exposure (using amber quartz or covering the laboratory material with aluminum foil) in

167 order to minimize brominated compounds degradation.

168 RESULTS AND DISCUSSION

169 Effect of $\mathrm{CuBr}_{2}$ on combustion

170 Figure 1 presents the decomposition of all the samples heated in synthetic air $\left(\mathrm{N}_{2}: \mathrm{O}_{2}=\right.$

$1714: 1)$ at $10 \mathrm{~K} / \mathrm{min}$. Similar residues are obtained with activated carbon 'C', mixtures with a 172 very low $\mathrm{CuBr}_{2}$ content ' $\mathrm{C}+$ traceB' and ' $\mathrm{C}+1 \mathrm{~B}$ ', and the pyrolyzed sample 173 'py+wash(C+50B)' (approx. 5 wt. \%, which corresponds to the ash content of the carbon), 174 whereas it is $22 \mathrm{wt} . \%$ for sample ' $\mathrm{C}+50 \mathrm{~B}$ ', and $32 \mathrm{wt} . \%$ in the case of $\mathrm{CuBr}_{2}$. $\mathrm{The}$ 175 mixture of carbon and $\mathrm{CuBr}_{2}$ in sample ' $\mathrm{C}+50 \mathrm{~B}$ ' leads to a final residue that is comprised 176 between that from active carbon and pure $\mathrm{CuBr}_{2}$.

177 As can be seen, pure $\mathrm{CuBr}_{2}$ presents two weight loss steps, corresponding to the 178 following reactions ${ }^{21}$ : when heated at more than $150^{\circ} \mathrm{C}, \mathrm{CuBr}_{2}$ loses $\mathrm{Br}_{2}$ to give $\mathrm{CuBr}$, 179 which in air gives $\mathrm{CuO}$ at a temperature above $400{ }^{\circ} \mathrm{C}$. These reactions are also observed in 180 sample ' $\mathrm{C}+50 \mathrm{~B}$ ' (at temperatures slightly higher, due to the mixture with active carbon), 181 while the oxidation of the carbon occurs at an intermediate step (beginning at about $\left.182265^{\circ} \mathrm{C}\right)$. 


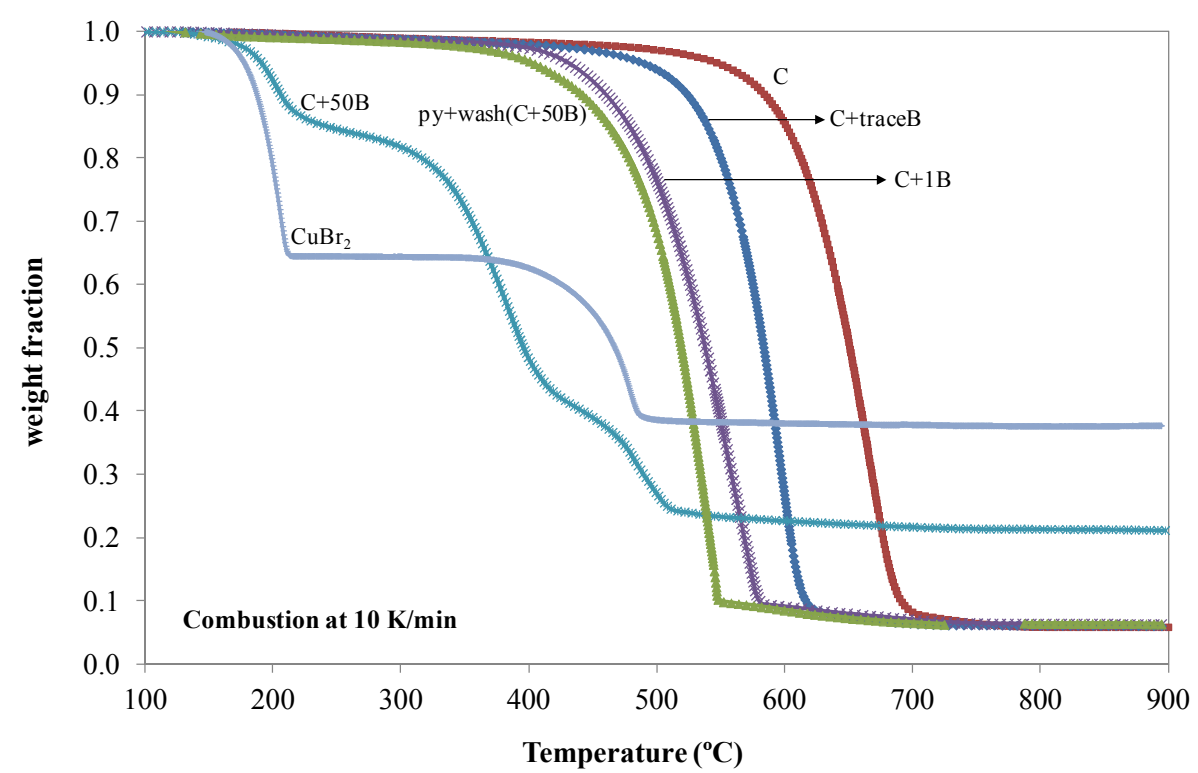

183

184 Figure 1. Combustion runs $\left(\mathrm{N}_{2}: \mathrm{O}_{2}=4: 1\right)$ at $10 \mathrm{~K} / \mathrm{min}$ with the following samples:

185 activated carbon ' $\mathrm{C}$ ', activated carbon with trace amounts of $\mathrm{CuBr}_{2}$ ' $\mathrm{C}+$ traceB', activated

186 carbon with 1 wt. $\% \mathrm{CuBr}_{2}$ ' $\mathrm{C}+1 \mathrm{~B}$ ', activated carbon with 50 wt. \% $\mathrm{CuBr}_{2}$ ' $\mathrm{C}+50 \mathrm{~B}$ ',

187 activated carbon +50 wt. $\% \mathrm{CuBr}_{2}$ pyrolyzed and washed 'py+wash $(\mathrm{C}+50 \mathrm{~B})$ ' and

188 copper(II) bromide $\left(\mathrm{CuBr}_{2}\right)$.

189 Table 1 presents the temperatures of maximum weight loss rate $\left(T_{\max }\right)$ at $10 \mathrm{~K} / \mathrm{min}$ for

190 the different samples, as well as those obtained in the previous work ${ }^{10}$ when studying

191 chlorinated dioxins production by addition of $\mathrm{CuCl}_{2}$ or $\mathrm{CuO}$. Note that the maximum

192 oxidation rate refers to the oxidative breakdown of the carbonaceous species without

193 considering the thermal decomposition of $\mathrm{CuCl}_{2}$ or $\mathrm{CuBr}_{2}$, as can be verified in Figure 1,

194 by comparing the decomposition in air of each sample prepared with that of metal halides.

195

196

197 
198 Table 1. Comparison between temperatures of maximum oxidative decomposition rate

$199\left(\mathrm{~T}_{\max }\right)$ of activated carbon in the presence of different copper halides (some data from

200 Conesa et al. $\left.{ }^{10}\right)$.

\begin{tabular}{|c|c|c|c|}
\hline \multicolumn{4}{|c|}{ Combustion runs performed at $10 \mathrm{~K} / \mathrm{min}$} \\
\hline Sample & Material & $\mathbf{T}_{\max }\left({ }^{\circ} \mathrm{C}\right)$ & $\Delta \mathbf{T}_{\max }$ \\
\hline $\mathrm{C}$ & Activated carbon $(\mathrm{C})$ & 655 & - \\
\hline$* *$ & $\mathrm{C}+50$ wt. $\% \mathrm{CuCl}_{2}$ pyrolyzed ${ }^{*}$ and washed & 485 & -170 \\
\hline ** & $\mathrm{C}+0.15$ wt. $\% \mathrm{CuCl}_{2}$ & 604 & -51 \\
\hline $\mathrm{C}+50 \mathrm{~B}$ & $\mathrm{C}+50$ wt. $\% \mathrm{CuBr}_{2}$ & 371 & -284 \\
\hline $\mathrm{py}+\mathrm{wash}(\mathrm{C}+50 \mathrm{~B})$ & $\mathrm{C}+50$ wt. $\% \mathrm{CuBr}_{2}$ pyrolyzed ${ }^{*}$ and washed & 508 & -147 \\
\hline $\mathrm{C}+1 \mathrm{~B}$ & $\mathrm{C}+1$ wt. $\% \mathrm{CuBr}_{2}$ & 535 & -120 \\
\hline $\mathrm{C}+$ traceB & $\mathrm{C}+0.15$ wt. $\% \mathrm{CuBr}_{2}$ & 577 & -78 \\
\hline
\end{tabular}

First of all, it is clear that the presence of $\mathrm{CuBr}_{2}$ accelerates the oxidative breakdown of

202 the carbonaceous structure, as well as $\mathrm{CuCl}_{2}$ does. A decrease in the temperature of

203 maximum carbon oxidation rate of almost $290{ }^{\circ} \mathrm{C}$ has been observed in the sample

204 consisting of carbon in the presence of $50 \mathrm{wt} \% \mathrm{CuBr}$. For the oxidation of the pyrolyzed

205 sample a decrease of $147^{\circ} \mathrm{C}$ is observed, whereas in the presence of metal chloride the

206 decrease was of $170{ }^{\circ} \mathrm{C}$. If samples with presence of trace amounts of metal halides are

207 compared, it is observed that sample with bromine (temperature decrease of $78^{\circ} \mathrm{C}$ ) is

208 slightly more reactive than sample with chlorine (temperature decrease of $51{ }^{\circ} \mathrm{C}$ ).

209 Some authors $1,3,22$ already reported on the catalytic effect of copper chlorides,

210 accelerating the oxidative degradation process of carbon particles. Schwarz and Stieglitz 4

211 indicated that, without catalyst, the oxidation of carbon to yield $\mathrm{CO}_{2}$ occurs at $700{ }^{\circ} \mathrm{C}$, but

212 it showed a peak temperature of $345^{\circ} \mathrm{C}$ in presence of copper (in a sample of fly ash from

213 a municipal waste incinerator). In a model mixture with charcoal and $\mathrm{KBr}$, the oxidation 
214 rate presented a maximum at $335^{\circ} \mathrm{C}$, which is similar to the value observed for sample

215 ' $\mathrm{C}+50 \mathrm{~B}$ ' in this study.

216 Comparing in Figure 1 the curves obtained in the oxidation of the sample prepared by

217 mixing the carbon with $\mathrm{CuBr}_{2}$ in excess (sample ' $\mathrm{C}+50 \mathrm{~B}$ '), with those for the material

218 pyrolyzed and washed (sample 'py+wash $(\mathrm{C}+50 \mathrm{~B})$ '), it is concluded that the presence of a

219 high amount of available bromine intensively accelerates the oxidative degradation. In the

220 sample washed to eliminate the excess, some copper and bromine remains bonded to the

221 carbonaceous structure provoking an acceleration of the carbon oxidation process, but not

222 as intense as in the case of the sample ' $\mathrm{C}+50 \mathrm{~B}$ '. Previous work ${ }^{10}$ indicated that copper(II)

223 ion is not the only responsible for the change in the reactivity of the carbon, but also the

224 presence of a halogen is necessary to accelerate the oxidative breakdown.

$225 \quad$ Kinetic study

226 A kinetic study was performed on the combustion of three of the previous samples: 'C', 227 ' $\mathrm{C}+50 \mathrm{~B}$ ' and 'py+wash $(\mathrm{C}+50 \mathrm{~B})$ '. As already commented, for sample 'py+wash $(\mathrm{C}+50 \mathrm{~B})$ ', 228 the pyrolytic step used for the preparation of the sample was carried out before the 229 combustion runs in the thermobalance.

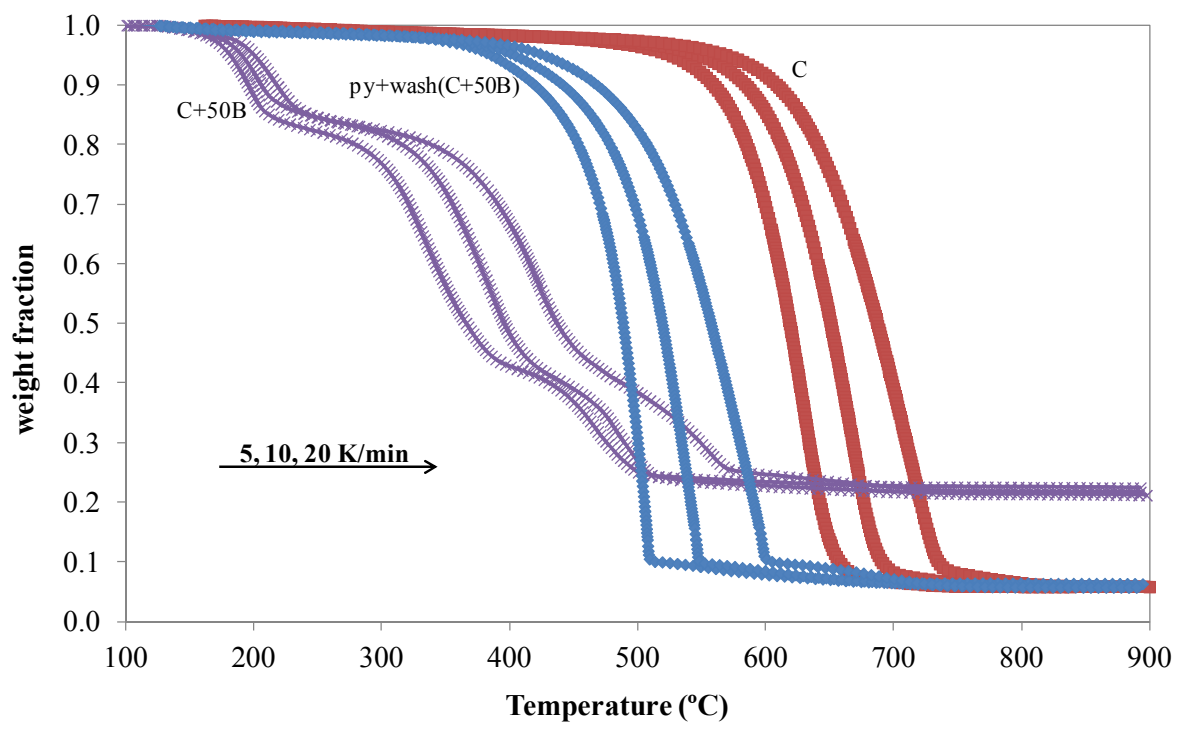


231 Figure 2. Combustion runs performed at 5, 10 and $20 \mathrm{~K} / \mathrm{min}$ with samples ' $\mathrm{C}$ ', ' $\mathrm{C}+50 \mathrm{~B}$ '

232 and 'py+wash $(\mathrm{C}+50 \mathrm{~B})$ '.

233 Figure 2 presents the combustion runs performed at three different heating rates in

234 order to obtain a detailed kinetic analysis ${ }^{23-25}$. As suggested in a previous study ${ }^{24}$, the 235 simplified kinetic equation for the chosen first-order single-reaction model can be written 236 as follows:

$237 \quad \frac{\mathrm{dw}}{\mathrm{dt}}=\mathrm{k}_{0} \exp \left(-\frac{\mathrm{E}}{\mathrm{RT}}\right)\left(\mathrm{w}-\mathrm{w}_{\infty}\right)$

238 where $w$ is the weight fraction (weight of the solid at any time divided by the initial 239 weight), $k_{0}$ is the pre-exponential factor $\left(\mathrm{s}^{-1}\right), E$ is the activation energy $(\mathrm{kJ} / \mathrm{mol}), R$ is the 240 gas constant $(\mathrm{kJ} / \mathrm{mol} \cdot \mathrm{K}), T$ is the temperature $(\mathrm{K})$ and $w_{\infty}$ is the weight fraction at time 241 infinity, which corresponds to the final residue of the experimental runs.

242 The objective function (O.F.) to minimize was the sum of the square differences 243 between experimental and calculated weight derivatives, as proposed in previous studies ${ }^{24}$. 244 In order to check the model validity, a previously reported ${ }^{10}$ variation coefficient (V.C.) 245 was calculated, which takes into account the number of experimental points correlated in 246 each model and the number of parameters to be fitted.

247 The Runge-Kutta fourth-order method was used to integrate the differential kinetic

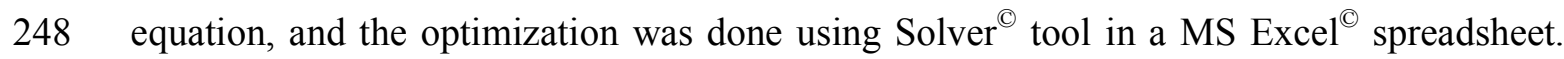
249 Table 2 shows the kinetics parameters obtained in the optimization. The values of the 250 variation coefficients are presented, which are quite low in all cases, bearing in mind that 251 the three curves obtained at different heating rates are considered.

252

253

254 
255 Table 2. Kinetic parameters for the combustion models and V.C. values.

\begin{tabular}{ccrc}
\hline Sample & $\mathbf{k}_{\mathbf{0}}\left(\mathbf{s}^{-\mathbf{1}}\right)$ & $\mathbf{E}(\mathbf{k J} / \mathbf{m o l})$ & V.C. $(\%)$ \\
\hline C & $3.31 \cdot 10^{6}$ & 158.4 & 1.1 \\
C+50B & $8.90 \cdot 10^{3}$ & 78.7 & 1.0 \\
py+wash $(\mathrm{C}+50 \mathrm{~B})$ & $2.49 \cdot 10^{5}$ & 118.9 & 1.9 \\
\hline
\end{tabular}

256

257 For the fitting of the curves obtained with sample ' $\mathrm{C}+50 \mathrm{~B}$ ' (i.e. activated carbon with a 25850 wt. $\%$ of $\mathrm{CuBr}_{2}$ ), only the oxidative degradation of the activated carbon is considered 259 (temperature range $265-440{ }^{\circ} \mathrm{C}$ ), by comparison with the curves obtained for $\mathrm{CuBr}_{2}$ alone 260 (see Figure 1).

261 In previous work ${ }^{10}$ analyzing the effect of $\mathrm{CuCl}_{2}$ we found similar pre-exponential 262 factors (in the order of $\left.10^{6} \mathrm{~s}^{-1}\right)$, as is the case of sample ' $\mathrm{C}$ ' and 'py+wash $(\mathrm{C}+50 \mathrm{~B})$ '. The 263 value of this parameter can be related to the number of active sites in the surface of the 264 carbon $^{26,27}$.

265 The values of the activation energy, that can be related to the strength of the bonds 266 formed $^{26,27}$, correlate well with the observations from the samples, indicating that the C-H 267 bond (sample ' $\mathrm{C}$ ') is quite stronger than the $\mathrm{C}-\mathrm{Br}$ bond (sample ' $\mathrm{C}+50 \mathrm{~B}$ '). The effect of 268 the pyrolysis and washing of ' $\mathrm{C}+50 \mathrm{~B}$ ' sample is to eliminate some bromine excess and 269 then to reduce the amount of $\mathrm{C}$-Br bonds; in this way, an intermediate value of activation 270 energy is found. In the case of $\mathrm{C}+\mathrm{CuCl}_{2}$ or $\mathrm{C}+\mathrm{CuO}+\mathrm{HCl}$ mixtures, higher activation 271 energies were found ( $>120 \mathrm{~kJ} / \mathrm{mol}$ in all cases), what suggests that the $\mathrm{C}-\mathrm{Br}$ bond is 272 weaker than $\mathrm{C}-\mathrm{Cl}$. These observations agree with the values of bond energies found in 273 literature $^{28}$.

274 The decomposition (in the presence of oxygen) of samples ' $\mathrm{C}+50 \mathrm{~B}$ ' and 275 'py+wash $(\mathrm{C}+50 \mathrm{~B})$ ' would produce different but small amounts of brominated aromatic 276 structures and a high amount of carbon oxides. In sample ' $\mathrm{C}+50 \mathrm{~B}$ ' the amount of bromine 
277 is so high that a lot of $\mathrm{C}-\mathrm{Br}$ bonds can be formed during the decomposition, and so a high

278 amount of brominated species is expected. Actually the reaction producing brominated

279 species and carbon oxides is the same, and can be represented by:

$280 \quad \mathrm{C}(\mathrm{Ar}, \mathrm{Br})+\mathrm{O}_{2} \rightarrow \mathrm{ArBr}+\mathrm{CO}_{2}$

281 where $C(\mathrm{Ar}, \mathrm{Br})$ represents macromolecular carbon with bromine and aromatic compounds.

282 This is the rate-controlling step and, as mentioned, a first-order kinetic law was used to 283 correlate the experimental data, where different activation energies for samples with 284 low/high amount of bromine are found.

285 Polybrominated dioxins and furan analysis and evolution with temperature

286 The PBDD/F analysis carried out comprised the quantitative determination of 13

287 different 2,3,7,8-substituted tetra- to octabrominated congeners (equivalent to the toxic 288 congeners of $\mathrm{PCDD} / \mathrm{Fs}$ ) and the corresponding total homologues.

289 As indicated above, sample 'py+wash $(\mathrm{C}+50 \mathrm{~B})$ ' was treated at 300,400 and $500{ }^{\circ} \mathrm{C}$ in 290 presence of air for 60 minutes in a horizontal laboratory reactor, obtaining a solid residue 291 of 81.7 wt. $\%, 49.7$ wt. $\%$ and 4.7 wt. \%, respectively.

292 Both the resin containing the volatiles evolved and the residual solid were analyzed for $293 \mathrm{PBDD} / \mathrm{Fs}$, as described in the Experimental section, and the values of total yields at the 294 different temperatures are shown in Figure 3. Maximum yield is found at $300{ }^{\circ} \mathrm{C}$, with the 295 emission of $91.7 \mathrm{ng} / \mathrm{g}$ of total $\mathrm{PBDD} / \mathrm{Fs}$, while at 400 and $500{ }^{\circ} \mathrm{C}$ the emissions are reduced 296 down to 12.7 and $32.8 \mathrm{ng} / \mathrm{g}$, respectively. The results are in accordance with the 297 phenomena observed by Heinbuch and Stieglitz ${ }^{11}$ who found a maximum production at ca. $298350{ }^{\circ} \mathrm{C}$, and in contrast with the maximum production of $\mathrm{PCDD} / \mathrm{Fs}$ found at $400{ }^{\circ} \mathrm{C}$ in 299 different studies ${ }^{3,5,10}$.

$300 \quad$ Figure 3 also presents the distribution of the produced PBDD/Fs between solid residue 301 (lower part of the bar) and gas phase (upper part of the bar) at the different temperatures. 
302 As expected, at low temperature the higher amounts are found in the solid residue, but as

303 temperature increases, emission in the gas phase is more and more important, while the 304 amount remaining in the solid phase decreases.

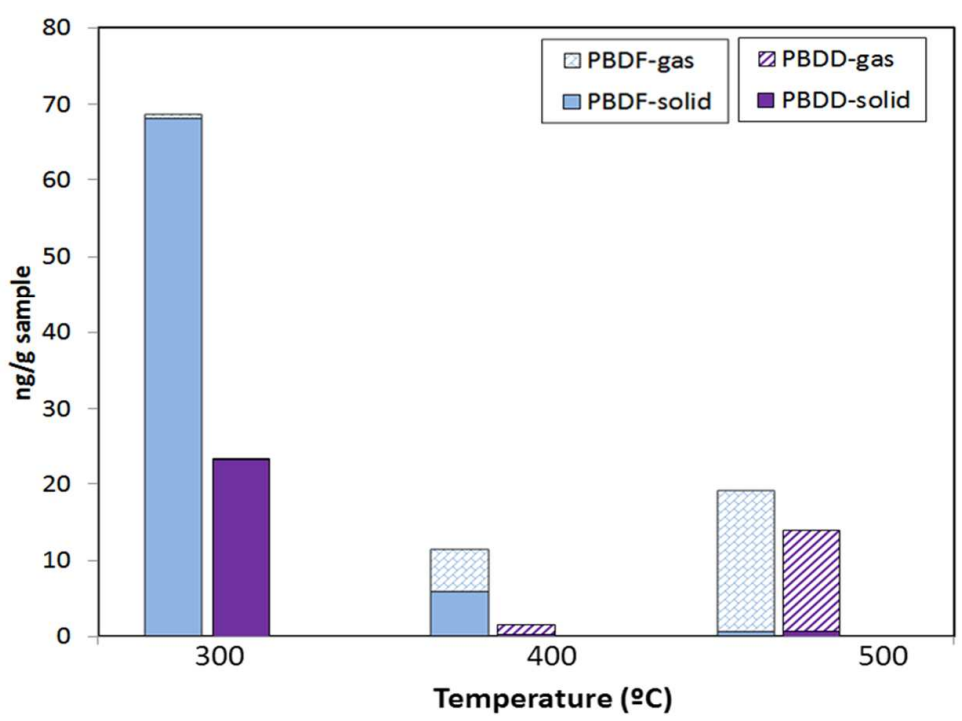

305

Figure 3. Evolution of total brominated dioxins (PBDDs) and furans (PBDFs) at the different temperatures. Partitioning of the evolved PBDDs and PBDFs between gas phase and solid residue is shown.

Comparing the results with those found for de novo formation of chlorinated species in similar conditions by Conesa et al. ${ }^{10}$, the amount of $\mathrm{D} / \mathrm{Fs}$ structures formed is approximately 10 times lower in the present study. Schüler and Jager $^{14}$ found formation rates of PBDD/Fs 4 to 20 times higher than those of their chlorinated analogues in a pilot incineration plant, but only mono- to tetrabrominated congeners were analyzed and, as in the present study, furans were more abundant than dioxins. This later observation is in accordance with a dioxin/furan ratio $<1$, characteristic of de novo synthesis ${ }^{6}$.

Table 3 shows the yields of the analyzed 2,3,7,8-substituted PBDD/Fs and the total yields for each homologue group found in the experiments at 300,400 and $500{ }^{\circ} \mathrm{C}$.

Table 3. Formation of $\mathrm{PBDD} / \mathrm{Fs}$ (ng/g sample) by de novo synthesis at different temperatures. 


\begin{tabular}{|c|c|c|c|}
\hline Temperature & $300^{\circ} \mathrm{C}$ & $400^{\circ} \mathrm{C}$ & $500^{\circ} \mathrm{C}$ \\
\hline \multicolumn{4}{|l|}{ Congeners } \\
\hline $2,3,7,8-\mathrm{TBDF}$ & 2.48 & 0.38 & 0.73 \\
\hline $1,2,3,7,8-\mathrm{PeBDF}$ & nd & nd & 0.002 \\
\hline $2,3,4,7,8-\mathrm{PeBDF}$ & 0.34 & 0.06 & 0.14 \\
\hline $1,2,3,4,7,8-\mathrm{HxBDF}$ & 0.17 & 0.07 & 0.78 \\
\hline $1,2,3,4,6,7,8-\mathrm{HpBDF}$ & 0.85 & 1.42 & 5.02 \\
\hline OBDF & nd & nd & 0.99 \\
\hline $2,3,7,8-\mathrm{TBDD}$ & 0.48 & 0.06 & 0.10 \\
\hline $1,2,3,7,8-P e B D D$ & nd & nd & 0.13 \\
\hline $1,2,3,4,7,8+1,2,3,6,7,8-\mathrm{HxBDD}$ & 0.35 & nd & 0.25 \\
\hline $1,2,3,7,8,9-\mathrm{HxBDD}$ & nd & nd & 0.07 \\
\hline $1,2,3,4,6,7,8-\mathrm{HpBDD}$ & 0.59 & 0.20 & 0.58 \\
\hline OBDD & nd & nd & 0.49 \\
\hline Total 2,3,7,8-PBDFs & 3.84 & 1.92 & 7.66 \\
\hline Total 2,3,7,8-PBDDs & 1.43 & 0.25 & 1.63 \\
\hline Total 2,3,7,8-PBDD/Fs & 5.27 & 2.17 & 9.29 \\
\hline \multicolumn{4}{|l|}{ Homologues } \\
\hline Total TBDF & 52.0 & 4.85 & 4.78 \\
\hline Total PeBDF & 7.56 & 1.47 & 3.87 \\
\hline Total HxBDF & 4.07 & 2.56 & 3.93 \\
\hline Total HpBDF & 4.73 & 2.33 & 5.41 \\
\hline OBDF & nd & nd & 0.99 \\
\hline Total TBDD & 16.9 & 1.30 & 8.35 \\
\hline Total PeBDD & 3.93 & nd & 2.61 \\
\hline Total HxBDD & 1.93 & nd & 1.82 \\
\hline Total HpBDD & 0.59 & 0.20 & 0.58 \\
\hline OBDD & nd & nd & 0.49 \\
\hline Total PBDFs & 68.4 & 11.2 & 19.0 \\
\hline Total PBDDs & 23.3 & 1.49 & 13.9 \\
\hline Total PBDD/Fs & 91.7 & 12.7 & 32.8 \\
\hline
\end{tabular}

321 Figure 4 shows the relative contribution of the different 2,3,7,8-bromosubstituted

322 congeners (equivalent to the toxic congeners of chlorinated dioxins) and the total

323 homologues. Regarding furans, tetrabrominated homologues are the most abundant at

$324300{ }^{\circ} \mathrm{C}$, with formation of $2.48 \mathrm{ng} / \mathrm{g}$ of 2,3,7,8-TeBDF, if we look at the 2,3,7,8-congeners.

325 At $400{ }^{\circ} \mathrm{C}$, tetrafurans are also predominant, but a shift in the bromination degree is

326 observed toward hexa- and heptabrominted homologues, with $1.42 \mathrm{ng} / \mathrm{g}$ of $1,2,3,4,6,7,8$ -

327 HpBDF being the most abundant toxic isomer. The increase in the bromination degree is

328 more pronounced at $500{ }^{\circ} \mathrm{C}$, with heptafurans as the most abundant homologues and 
$3295.02 \mathrm{ng} / \mathrm{g}$ of $1,2,3,4,6,7,8-\mathrm{HpBDF}$; also a slight formation of OBDF is observed, which had

330 not been detected at lower temperatures.

331 As for dioxins, the profiles do not show that marked effect of temperature. Important

332 amounts of tetra- and heptabrominated congeners are found at $300{ }^{\circ} \mathrm{C}$, with $0.48 \mathrm{ng} / \mathrm{g}$ of

$3332,3,7,8-\mathrm{TeBDD}$ and $0.59 \mathrm{ng} / \mathrm{g}$ of $1,2,3,4,6,7,8-\mathrm{HpBDD}$ within the 2,3,7,8-substituted

334 congeners. Tetrabrominated dioxins are also dominant at 400 and $500{ }^{\circ} \mathrm{C}$, whereas

$3351,2,3,4,6,7,8-\mathrm{HpBDD}$ predominates in the toxic congeners $(0.20$ and $0.58 \mathrm{ng} / \mathrm{g}$

336 respectively). As in furans, OBDD is only found at $500^{\circ} \mathrm{C}$.

337 Other authors have also observed a higher degree of halogenation with increasing

338 temperature in the formation of dioxins and furans by de novo synthesis ${ }^{3-5}$. Luijk et al. ${ }^{5}$

339 linked that fact to the higher thermal energy needed for the formation of the compounds

340 with a higher halogenation degree.

341 In comparing the profiles with the ones obtained for PCDD/Fs in our previous work ${ }^{10}$,

342 the degree of halogenation at a set temperature is always lower in the case of bromine,

343 since the activation energy barrier for bromination is higher than for chlorination, as

344 indicated by Luijk et al. ${ }^{29}$. In addition, the formation of PBDFs of high bromination degree

345 is more difficult than the low brominated ones, and compared to the chlorinated ones, due

346 to steric hindrance in the molecule ${ }^{13}$. 

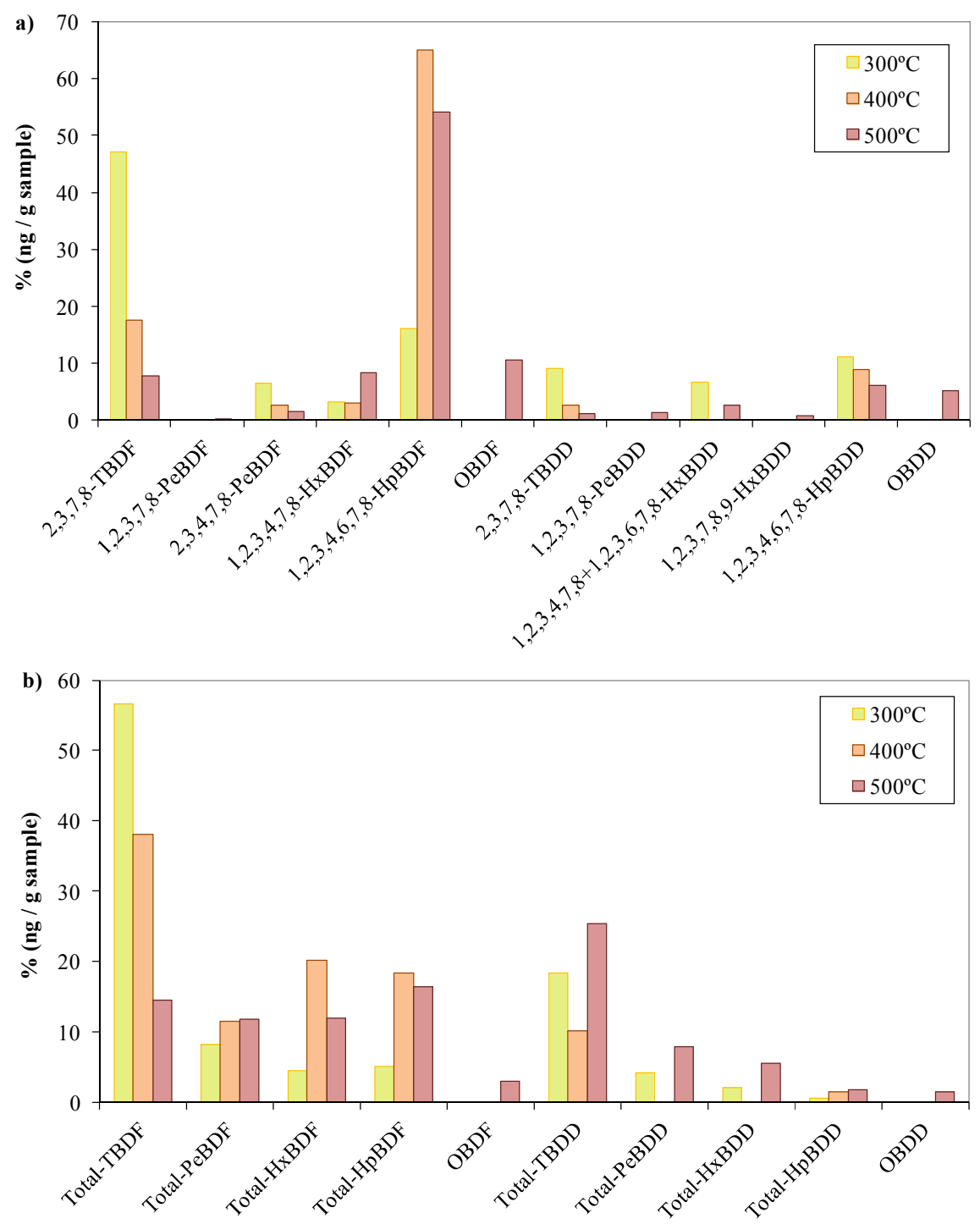

347 Figure 4. De novo synthesis of PBDD/Fs at different temperatures: a) Isomer profile of 2,3,7,8-brominated congeners and b) Total homologue profiles.

A simulation of the isothermal runs has been carried out using the optimal kinetic parameters obtained in the previous section (Table 2). The resulting curves, using an

351 estimated heating rate of $100 \mathrm{~K} / \mathrm{min}$ in the laboratory furnace until the final temperature is

352 reached $^{30}$, is shown in Figure 5. The predicted final weight fraction for each run 353 corresponds reasonably well with the remaining solid fraction measured after $60 \mathrm{~min}$ in the

354 laboratory reactor combustion experiments, which were $0.82,0.50$ and 0.05 , at 300,400 and $500^{\circ} \mathrm{C}$, respectively. 
356 Comparing with the simulation of the oxidation of an analogous sample (with $\mathrm{CuCl}_{2}$ 357 instead of $\mathrm{CuBr}_{2}$ ) presented by Conesa et al. ${ }^{10}$, as in the previous study, a quite low 358 degradation is observed at $300{ }^{\circ} \mathrm{C}$, whereas an intermediate weight loss is found at $400{ }^{\circ} \mathrm{C}$ 359 and almost complete at $500{ }^{\circ} \mathrm{C}$. The behavior and weight fraction of the sample prepared 360 with $\mathrm{CuBr}_{2}$ is similar to the one with $\mathrm{CuCl}_{2}$, but slightly lower at any time.

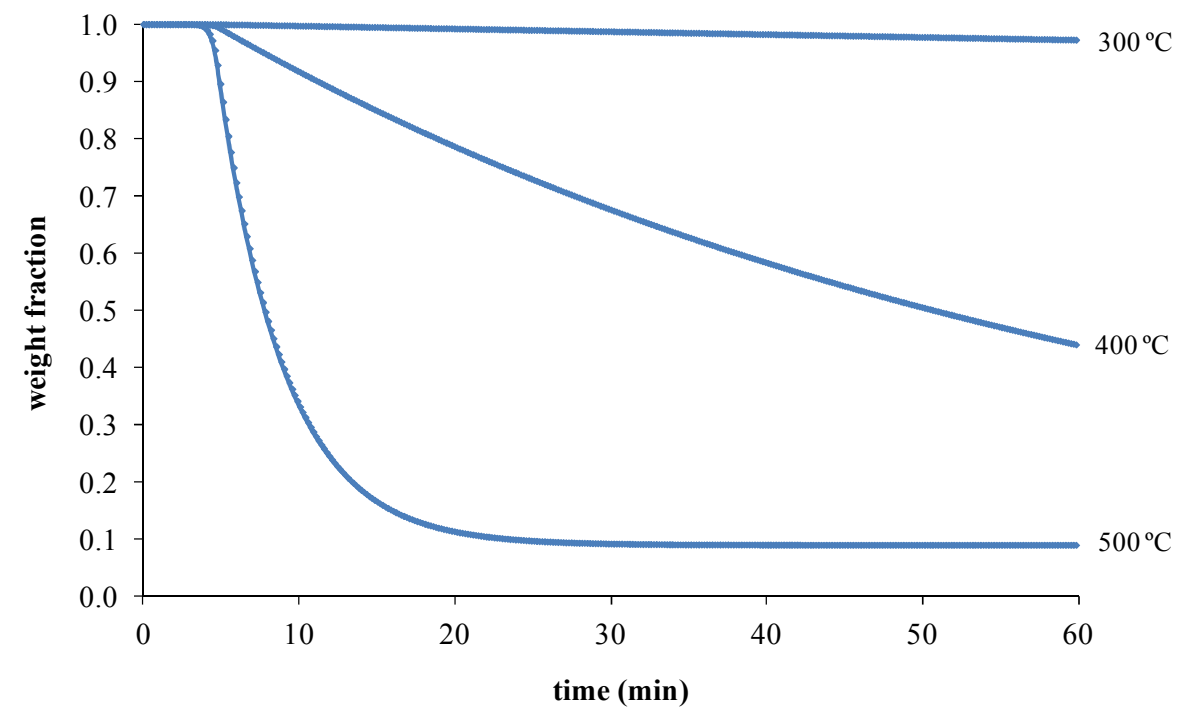

361

362 Figure 5. Simulated isothermal runs for the samples of activated carbon mixed with $50 \mathrm{wt}$. 363 $\%$ of $\mathrm{CuBr}_{2}$ (sample 'py+wash(C+50B)').

364 Considering the yields of brominated dioxins and furans formed by de novo pathway in 365 the present study, with a maximum at $300{ }^{\circ} \mathrm{C}$, it seems that this mechanism is favored at 366 low oxidative breakdown levels, i.e. when the carbonaceous surface begins to react with 367 oxygen but still has a definite structure. At increasing temperatures, when the oxidation of 368 the carbon is faster, formation of new PBDD/Fs decreases.

369 ACKNOWLEDGEMENTS

370 Support for this work was provided by the Generalitat Valenciana (Spain), research 371 project Prometeo/2009/043/FEDER, and by the Spanish MCT, research project 372 CTQ2008-05520.

373 REFERENCES 
374 1. Stieglitz, L.; Zwick, G.; Beck, J.; Bautz, H.; Roth, W., Carbonaceous particles in 375 fly ash -a source for the de-novo-synthesis of organochlorocompounds. Chemosphere 376 1989, 19, (1-6), 283-290.

377 2. Stieglitz, L.; Eichberger, M.; Schleihauf, J.; Beck, J.; Zwick, G.; Will, R., The 378 oxidative degradation of carbon and its role in the de-novo-synthesis of organohalogen 379 compounds in fly ash. Chemosphere 1993, 27, (1-3), 343-350.

380 3. Stieglitz, L., Selected topics on the de novo synthesis of PCDD/PCDF on fly ash. 381 Environmental Engineering Science 1998, 15, (1), 5-18.

382 4. Schwarz, G.; Stieglitz, L., Formation of organohalogen compounds in fly ash by 383 metal-catalyzed oxidation of residual carbon. Chemosphere 1992, 25, (3), 277-282.

384 5. Xhrouet, C.; Pirard, C.; De Pauw, E., De novo synthesis of polychlorinated 385 dibenzo-p-dioxins and dibenzofurans on fly ash from a sintering process. Environ. Sci. 386 Technol. 2001, 35, (8), 1616-1623.

387 6. Huang, H.; Buekens, A., On the mechanisms of dioxin formation in combustion 388 processes. Chemosphere 1995, 31, (9), 4099-4117.

389 7. Huang, H.; Buekens, A., De novo synthesis of polychlorinated dibenzo-p-dioxins 390 and dibenzofurans Proposal of a mechanistic scheme. Sci. Total Environ. 1996, 193, (2), $391 \quad 121-141$.

392 8. Tuppurainen, K.; Halonen, I.; Ruokojärvi, P.; Tarhanen, J.; Ruuskanen, J., 393 Formation of PCDDs and PCDFs in municipal waste incineration and its inhibition 394 mechanisms: A review. Chemosphere 1998, 36, (7), 1493-1511.

3959 9. Conesa, J. A.; Fullana, A.; Font, R., Reactivity of carbonaceous materials modified 396 by copper chloride addition. A thermogravimetric study. J. Anal. Appl. Pyrol. 2001, 58-59, $397 \quad 553-568$. 
10. Conesa, J. A.; Fullana, A.; Font, R., De novo-synthesis of PCDD/Fs by

399

400

401

402

403

404

405

406

407

408

409

410

411

412

413

414

415

416

417 thermogravimetry. Environ. Sci. Technol. 2002, 36, 263-269.

11. Heinbuch, D.; Stieglitz, L., Formation of brominated compounds on fly ash. Chemosphere 1993, 27, (1-3), 317-324.

12. Weber, R.; Kuch, B.; Ohno, T.; Sakurai, T., De novo synthesis of mixed brominated-chlorinated PXDD/PXDF. Organohalogen Compd. 2002, 56, 181-184.

13. Weber, R.; Kuch, B., Relevance of BFRs and thermal conditions on the formation pathways of brominated and brominated-chlorinated dibenzodioxins and dibenzofurans. Environment International 2003, 29, (6), 699-710.

14. Schüler, D.; Jager, J., Formation of chlorinated and brominated dioxins and other organohalogen compounds at the pilot incineration plant VERONA. Chemosphere 2004, $54,(1), 49-59$.

15. Shaub, W. M.; Tsang, W., Dioxin formation in incinerators. Environ. Sci. Technol. 1983, 17, (12), 721-730.

16. Blumenstock, M.; Zimmermann, R.; Schramm, K. W.; Kettrup, A., Influence of combustion conditions on the PCDD/F-, PCB-, PCBz- and PAH-concentrations in the post-combustion chamber of a waste incineration pilot plant. Chemosphere 2000, 40, (911), 987-993.

17. Gullett, B. K.; Lemieux, P. M., Role of combustion and sorbent parameters in prevention of polychlorinated dibenzo-p-dioxin and polychlorinated dibenzofuran formation during waste combustion. Environ. Sci. Technol. 1994, 28, (1), 107-118.

18. Du, B.; Zheng, M.; Tian, H.; Liu, A.; Huang, Y.; Li, L.; Ba, T.; Li, N.; Ren, Y.; Li, Y.; Dong, S.; Su, G., Occurrence and characteristics of polybrominated dibenzo-p-dioxins and dibenzofurans in stack gas emissions from industrial thermal processes. Chemosphere 2010, $80,(10), 1227-1233$. 
19. Xiao, H.-X.; Ma, Z.-Y.; Huang, Q.-X.; Jin, Y.-Q.; Chi, Y.; Yan, J.-H.; Ni, M.-J. In

424

425

426

427

428

429

430

431

432

433

434

435

436

437

438

439

440

441

442

443

444

445

446

Combustion of electronic wastes using a drop tube furnace, Electric Technology and Civil Engineering (ICETCE), 2011 International Conference on, 22-24 April 2011, 2011; 2011; pp 2988-2991.

20. Aracil, I.; Font, R.; Conesa, J. A., Semivolatile and volatile compounds from the pyrolysis and combustion of polyvinyl chloride. J. Anal. Appl. Pyrol. 2005, 74, (1-2), 465478.

21. Zuckerman, J. J.; Hagen, A. P., Eds. Inorganic reactions and methods. Volume 4: Formation of bonds to halogens (Part 2). VCH Publishers, Inc.: 1991.

22. Luijk, R.; Akkerman, D. M.; Slot, P.; Olie, K.; Kapteijn, F., Mechanism of formation of polychlorinated dibenzo-p-dioxins and dibenzofurans in the catalyzed combustion of carbon. Environ. Sci. Technol. 1994, 28, (2), 312-321.

23. Conesa, J. A.; Font, R.; Fullana, A.; Caballero, J. A., Kinetic model for the combustion of tyre wastes. Fuel 1998, 77, (13), 1469-1475.

24. Conesa, J. A.; Marcilla, A.; Caballero, J. A.; Font, R., Comments on the validity and utility of the different methods for kinetic analysis of thermogravimetric data. J. Anal. Appl. Pyrol. 2001, 58-59, 617-633.

25. Caballero, J. A.; Font, R.; Marcilla, A.; Conesa, J. A., New kinetic model for thermal decomposition of heterogeneous materials. Ind. Eng. Chem. Res. 1995, 34, (3), 806-812.

26. Font, R.; García, A. N., Application of the transition state theory to the pyrolysis of biomass and tars. J. Anal. Appl. Pyrol. 1995, 35, (2), 249-258.

27. Dellinger, B.; Taylor, P. H., Chemical aspects of combustion of hazardous wastes. Central European Journal of Public Health 1998, 6, (2), 79-87. 
447 28. Lide, D. R., Eds. CRC Handbook of Chemistry and Physics. 74th ed.; CRC Press, 448 Inc.: Florida, 1993.

449 29. Luijk, R.; Dorland, C.; Smit, P.; Jansen, J.; Govers, H. A. J., The role of bromine in 450 the de novo synthesis in a model fly ash system. Chemosphere 1994, 28, (7), 1299-1309.

451 30. Fullana, A.; Conesa, J. A.; Font, R.; Sidhu, S., Formation and destruction of 452 chlorinated pollutants during sewage sludge incineration. Environ. Sci. Technol. 2004, 38, 453 (10), 2953-2958.

454

455 